\title{
TERAPI FOOT MASSAGE UNTUK MENURUNKAN DAN MENSTABILKAN TEKANAN DARAH PADA PENDERITA HIPERTENSI
}

\section{FOOT MASSAGE THERAPY TO REDUCE AND STABILATE BLOOD PRESSURE IN HYPERTENSION PATIENTS}

\author{
Kamaliah Ainun*, Kristina, Srimis Leini \\ Universitas Haji Sumatera Utara, Deli Serdang \\ *Email: Kamaliahainun21@gmail.com \\ (Diterima 14-08-2021; Disetujui 15-09-2021)
}

\begin{abstract}
ABSTRAK
Hipertensi merupakan penyakit yang banyak diderita oleh masyarakat disebut dengan the silent killer karena sering tidak meimbulkan gejala yang khas. Penderita Hipertensi berpedoman pada standar pengobatan dan merubah pola hidup agar tekanan darah tetap stabil. Hipertensi dapat menyebabkan komplikasi yang berbahaya jika tidak ditangani dengan baik khususnya organ organ vital pada tubuh. Terapi Foot Massage yang merupakan salah satu terapi komplementer berfungsi untuk menurunkan dan menstabilkan tekanan darah karena dapat memberikan efek relaksasi pada otot-otot yang kaku sehingga terjadi vasodilatasi yang menyebabkan tekanan darah turun secara stabil. Penderita Hipertensi cukup banyak di kelurahan Tanah Merah Kecamatan Binjai Selatan Kota Binjai tahun 2020, kegiatan pengabdian masyarakat bertujuan meningkatkan pengetahuan masyarakat terhadap penatalaksanaan terapi foot massage yang merupakan salah satu terapi komplementer. Peserta yang mengikuti sebanyak 25 orang setelah malaksanakan terapi foot massage 3 hari berturut turut selama 15 menit nyeri kepala hilang, badan terasa ringan, rileks dan hasil tekanan darah systole menjadi stabil.
\end{abstract}

Kata kunci: Hipertensi, Terapi Foot Massage

ABSTRACT

Hypertension is a disease that many people suffer from, it is called the silent killer because it often does not cause typical symptoms. Patients with hypertension are guided by standard treatment and change their lifestyle so that blood pressure remains stable. Hypertension can cause dangerous complications if not handled properly, especially the vital organs in the body. Foot massage therapy which is one of the complementary therapies serves to reduce and stabilize blood pressure because it can provide a relaxing effect on stiff muscles so that vasodilation occurs which causes blood pressure to fall steadily. There are quite a lot of hypertension sufferers in the Tanah Merah village, South Binjai District, Binjai City in 2020, community service activities aim to increase public knowledge about the management of foot massage therapy which is one of the complementary therapies. Participants who followed as many as 25 people after carrying out foot massage therapy 3 days in a row for 15 minutes the headache disappeared, the body felt light, relaxed and the results of systolic blood pressure became stable.

Keywords: Hypertension, Foot Massage Therapy

\section{PENDAHULUAN}

Hipertensi didefinisikan sebagai peningkatan tekanan darah secara abnormal, baik tekanan diastol maupun tekanan sistol. Menurut WHO batas normal tekanan darah adalah 120-140 mmHg tekanan sistol dan 80-90 mmHg tekanan diastol. Seseorang dinyatakan mengidap hipertensi bila tekanan darahnya $>140 / 90 \mathrm{mmHg}$.

Hipertensi merupakan salah satu penyakit kardiovaskuler yang paling banyak diderita oleh masyarakat dan pada umumnya tidak merasakan keluhan, sehingga disebut sebagai the silent killer. Faktor yang mempengaruhi hipertensi yaitu usia, genetik, dan 
Terapi Foot Massage Untuk Menurunkan dan Menstabilkan Tekanan Darah pada Penderita Hipertensi

Kamaliah Ainun, Kristina, Srimis Leini

lingkungan yang berdampak pada keselamatan jiwa yang mengakibatkan meningkatnya angka morbiditas dan angka mortalitas (Yanti, 2019).

Lingkungan menjadi salah satu faktor risiko yang mempengaruhi timbulnya penyakit hipertensi yang meliputi: stres, obesitas, status gizi, minum kopi, kualitas tidur dan merokok. Individu yang tidak mampu mengontrol tekanan darah, dan tidak berobat secara teratur memiliki risiko terkena komplikasi, dan komplikasi yang ditimbulkan akibat hipertensi yaitu stroke pada hipertensi kronik, infark miocard, dan gagal ginjal jika terjadi kerusakan akibat tekanan tinggi pada kapiler-kapiler ginjal (Erfiana, 2015).

Berdasarkan survey World Health Organization (WHO) tahun 2015-2018, menunjukkan bahwa penderita hipertensi di dunia mencapai 1,13 miliar, artinya 1 dari 3 orang di dunia terdiagnosis hipertensi. Penderita hipertensi semakin meningkat setiap tahunnya, diperkirakan pada tahun 2025 mencapai 1,5 miliar menderita hipertensi, dengan perkiraan 10,44 juta orang meninggal akibat hipertensi dan komplikasi setiap tahunnya. Data WHO didukung oleh data Institute for Health Metrics and Evaluation (IHME) bahwa di Indonesia 1,7 juta kematian di Indonesia dengan faktor risiko yang menyebabkan kematian adalah tekanan darah (hipertensi) sebesar 23,7\%, hiperglikemia sebesar 18,4\%, merokok sebesar 12,7\% dan obesitas sebesar 7,7\%. Riset Kesehatan Dasar tahun 2018, menunjukkan prevalensi hipertensi di Indonesia mencapai 34,1\% berdasarkan kriteria pengukuran tekanan darah penduduk usia $\geq 18$ tahun. Prevalensi hipertensi di Provinsi Jawa Barat berdasarkan kriteria pengukuran tekanan darah penduduk usia $\geq 18$ tahun mencapai 40\% dan menduduki peringkat ke-2 di Indonesia.

Hipertensi perlu mendapatkan perhatian khusus dan penanganan yang komprehensif mulai dari usaha preventif, promotif, kuratif dan rehabilitatif (Arianto, 2018). Penanganan hipertensi yang komprehensif bertujuan untuk menurunkan tekanan darah, meliputi terapi konvensional dan terapi non konvensional. Terapi konvensional merupakan terapi dengan pemberian obat-obatan yaitu obat anti hipertensi, sedangkan terapi non konvensional merupakan terapi komplementer yang dapat dilakukan dengan bekam, akupuntur, tanaman tradisional, akupresur, dan pijat (massage) (Ardiansyah, 2019).

Terapi pijat atau massage adalah salah satu terapi komplementer yang saat ini digunakan untuk hipertensi. Massage merupakan terapi paling efektif untuk menurunkan tekanan darah pada hipertensi karena dapat menimbulkan efek relaksasi pada otot-otot yang kaku sehingga terjadi vasodilatasi yang menyebabkan tekanan darah turun secara stabil. Macam-macam metode massage yaitu metode Swedish massage, aroma massage, massage therapy, accupoint massage, scalp massage, without massage, back massage, 
classic massage, single session massage, mechanical massage, foot massage, dan whole body massage (Ardiansyah, 2019).

Foot massage merupakan salah satu terapi komplementer yang aman dan mudah diberikan dan mempunyai efek meningkatkan sirkulasi, mengeluarkan sisa metabolisme, meningkatkan rentang gerak sendi, mengurangi rasa sakit, merelaksasikan otot dan memberikan rasa nyaman pada pasien (Afianti, 2017). Foot massage adalah manipulasi jaringan lunak pada kaki secara umum dan tidak terpusat pada titik-titik tertentu pada telapak kaki yang berhubungan dengan bagian lain pada tubuh (Abduliansyah, 2018). Foot massage bertujuan untuk menurunkan tekanan darah, mengurangi kegiatan jantung dalam memompa, dan mengurangi mengerutnya dinding-dinding pembuluh nadi halus sehingga tekanan pada dinding-dinding pembuluh darah berkurang dan aliran darah menjadi lancar sehingga tekanan darah akan menurun (Patria, 2019).

Berdasarkan survey yang dilakukan di Kelurahan Tanah Merah Kecamatan Binjai Selatan Kota Binjai 2020 banyak yang menderita Hipertensi khususnya lansia. Penderita hipertensi merasakan nyeri kepala, badan terasa lemah dan tekanan darah tidak stabil, bahkan cenderung tinggi. Setelah didata terdapat 25 orang yang menderita hipertensi dan belum pernah melakukan terapi foot massage.

Adapun tujuan pengabdian adalah untuk menambah pengetahuan, peserta bisa melakukan terapi foot massage dengan standar operasional prosedur yang benar sehingga dapat menstabilkan tekanan darah, mengurangi rasa nyeri dan membuat tubuh lebih rileks.

\section{BAHAN DAN METODE}

Data hasil survey dijadikan sebagai acuan dalam melaksanakan kegiatan pengabdian. Pelaksanaan terapi foot massage dilakukan di salah satu rumah kader karena tempat yang memungkinkan untuk dilakukan terapi foot massage yang dilaksanakan selama 3 hari berturut turut selama 15 menit dengan menggunakan video, leaflet, laptop, LCD projector, spygnomanometer, stetoskop, handuk kecil, dan baby oil.

Prosedur foot massage dimulai dari persiapan, mempersiapkan pasien, dan melakukan foot massage.

\section{Persiapan Pasien adalah sebagai berikut:}

Melakukan pemeriksaan tekanan darah peserta (penderita hipertensi ringan dan sedang) sebelum melakukan massage kaki dan mencatat hasil. 
Terapi Foot Massage Untuk Menurunkan dan Menstabilkan Tekanan Darah pada Penderita Hipertensi

Kamaliah Ainun, Kristina, Srimis Leini

\section{Prosedur Pelaksanaan Foot Massage adalah sebagai berikut:}

1. Tempatkan handuk di bawah paha dan tumit.

2. Melumuri kedua telapak tangan dengan lotion atau minyak baby oil.

3. Lakukan pemijitan kaki dimulai dari telapak kaki sampai dengan bagian jari-jari kaki selama 15 detik di setiap bagian kaki.

4. Observasi tingkat kenyamanan pasien pada saat dilakukan massage.

\section{Langkah-langkah Foot Massage adalah sebagai berikut:}

\begin{tabular}{lll}
\hline No & \multicolumn{1}{c}{ Metode } & \multicolumn{1}{c}{ Langkah-langkah Foot Massage } \\
\hline 1 & $\begin{array}{l}\text { Dengan menggunakan bagian tumit telapak tangan peneliti, peneliti } \\
\text { menggosok dan memijat telapak kaki pasien secara perlahan dari arah } \\
\text { dalam ke arah sisi luar kaki pada bagian terluas kaki kanan selama } 15 \\
\text { detik. }\end{array}$ \\
\hline 2 & $\begin{array}{l}\text { Dengan menggunakan tumit telapak tangan peneliti di bagian yang } \\
\text { sempit dari kaki kanan, peneliti menggosok dan memijat secara perlahan } \\
\text { bagian telapak kaki pasien dari arah dalam ke sisi luar kaki selama } 15 \\
\text { detik. }\end{array}$
\end{tabular}

3

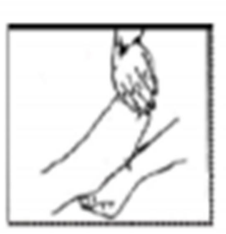

Pegang semua jari-jari kaki oleh tangan kanan, dan tangan kiri menopang tumit pasien, kemudian peneliti memutar pergelangan kaki tiga kali searah jarum jam dan tiga kali ke arah berlawanan arah jarum jam selama 15 detik.

Tahan kaki di posisi yang menunjukkan ujung jari kaki mengarah keluar
(menghadap peneliti), gerakan maju dan mundur tiga kali selama 15
detik. Untuk mengetahui fleksibilitas.



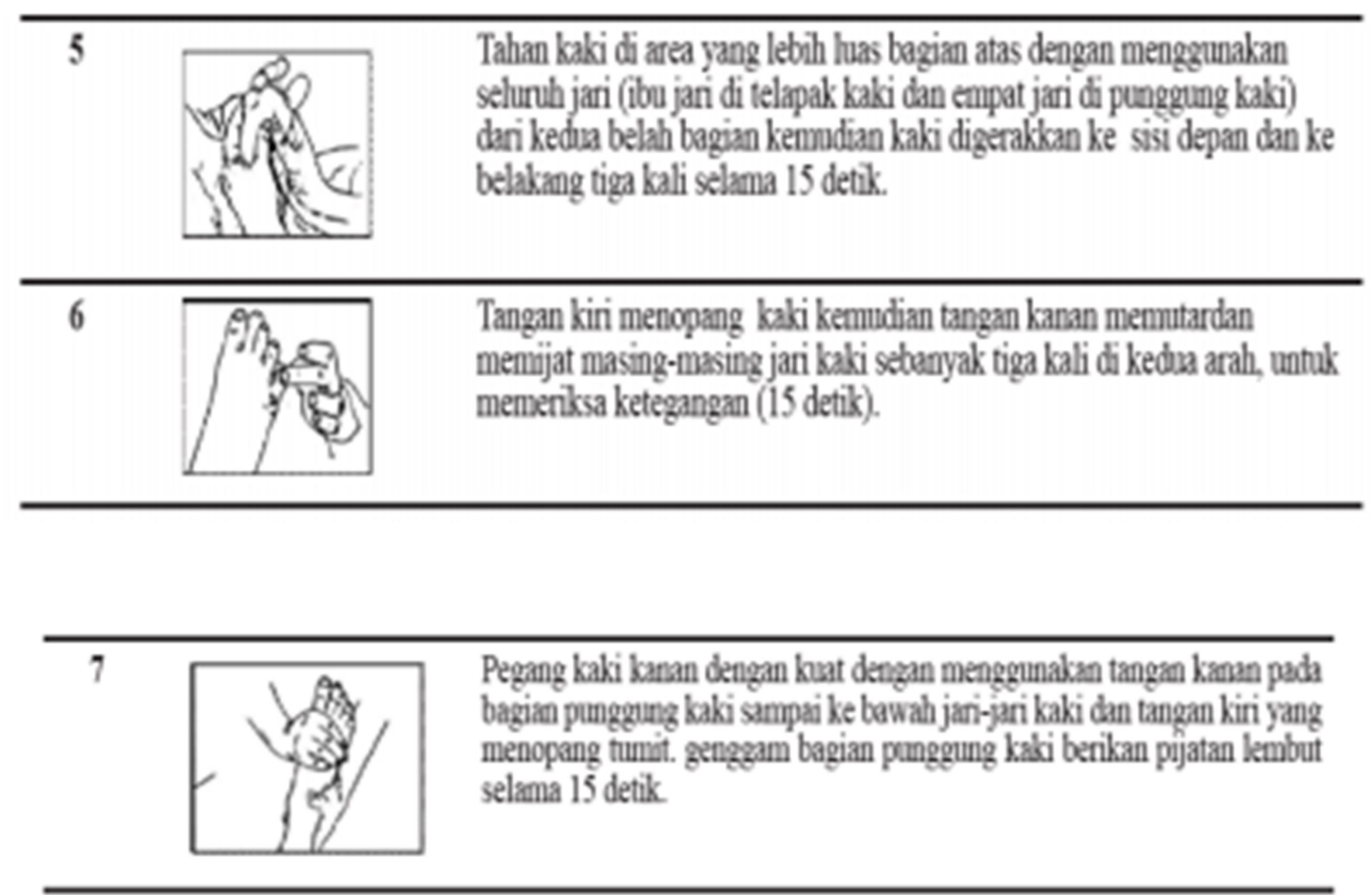

Pegang kaki kanan dengan kuat dengan menggunakan tangan kaman pada bagian punggung kaki sampai ke bawah jari-jari kaki dan tangan kiri yang menopang tumit. gengzam bagian punggung kaki berikan pjatan lembut selama 15 detik.

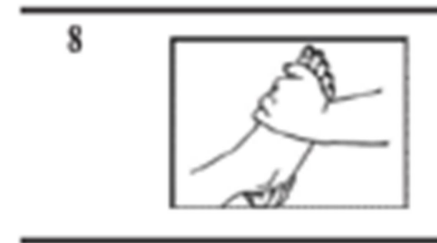

Posisi tangan berganti, tanzan kanan menopang tumit dan tanzan kiri yang menggenggang punggung kaki sampai bawah jari kaki kemudian di pijat dengan lembut selama 15 detik.

Menopang tumit menggunakan tangan kiri dan dengan menggunakan
tangan kanan untuk memutar setiap searah jarum jam kaki dan betlawanan
arah jarum jam serta menerapkan tekanan lembut selama 15 detik.

Gambar 1. Langkah-Langkah Foot Massage (Puthusseril, 2006) 
Terapi Foot Massage Untuk Menurunkan dan Menstabilkan Tekanan Darah pada Penderita Hipertensi

Kamaliah Ainun, Kristina, Srimis Leini

\section{HASIL DAN PEMBAHASAN}

Terapi foot massage dilaksanakan di kelurahan Tanah Merah Kecamatan Binjai Selatan Kota Binjai, jumlah peserta 25 lansia dengan hipertensi. Kegiatan dilaksanakan pada salah satu rumah kader 3 hari berturut turut selama 15 sampai dengan 30 menit, jadwal terapi foot massage dilakukan pada sore hari jam 14.00 - 14.30 wib.

Kegiatan dimulai dengan memberikan pemaparan pengertian, tujuan, manfaat dan cara melakukan terapi foot massage dengan melihat video, leaflet dan memperhatikan praktikan yang langsung diperagakan oleh tim pengabdian.

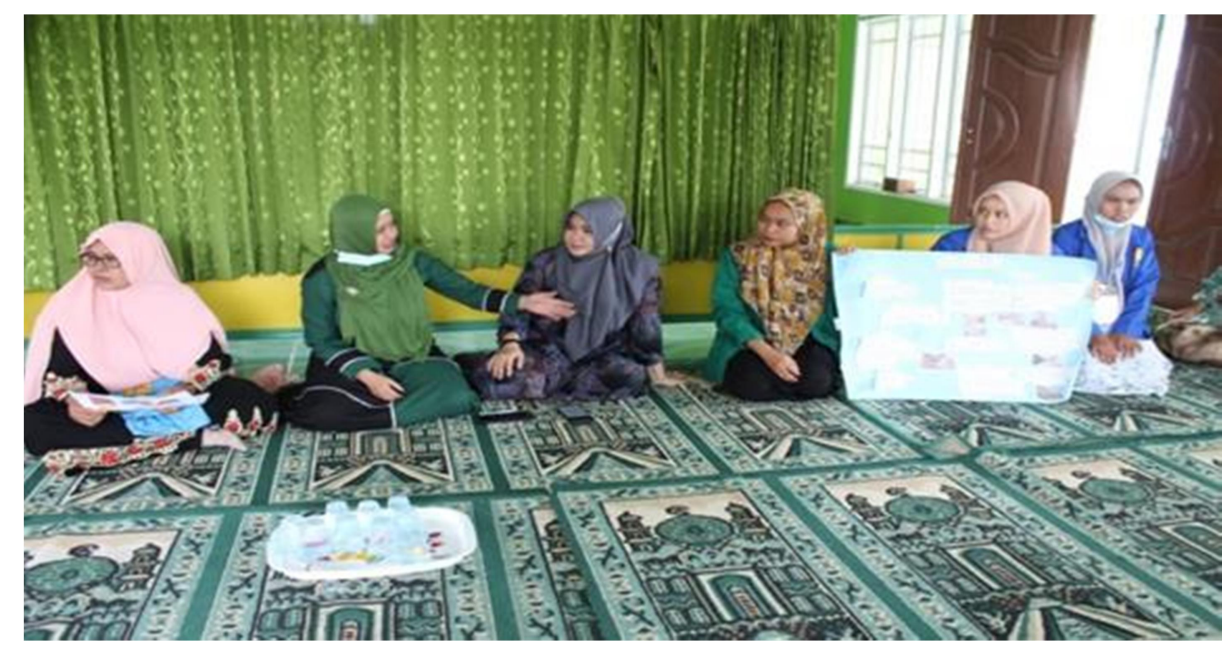

Gambar 2. Memaparkan Pengertian, Tujuan, dan Manfaat Terapi Foot Massage

Setelah memberikan pemaparan pengertian, tujuan, manfaat terapi foot massage, dengan menggunakan leaflet dan video maka para peserta membuat posisi lingkaran agar bisa para praktikan.

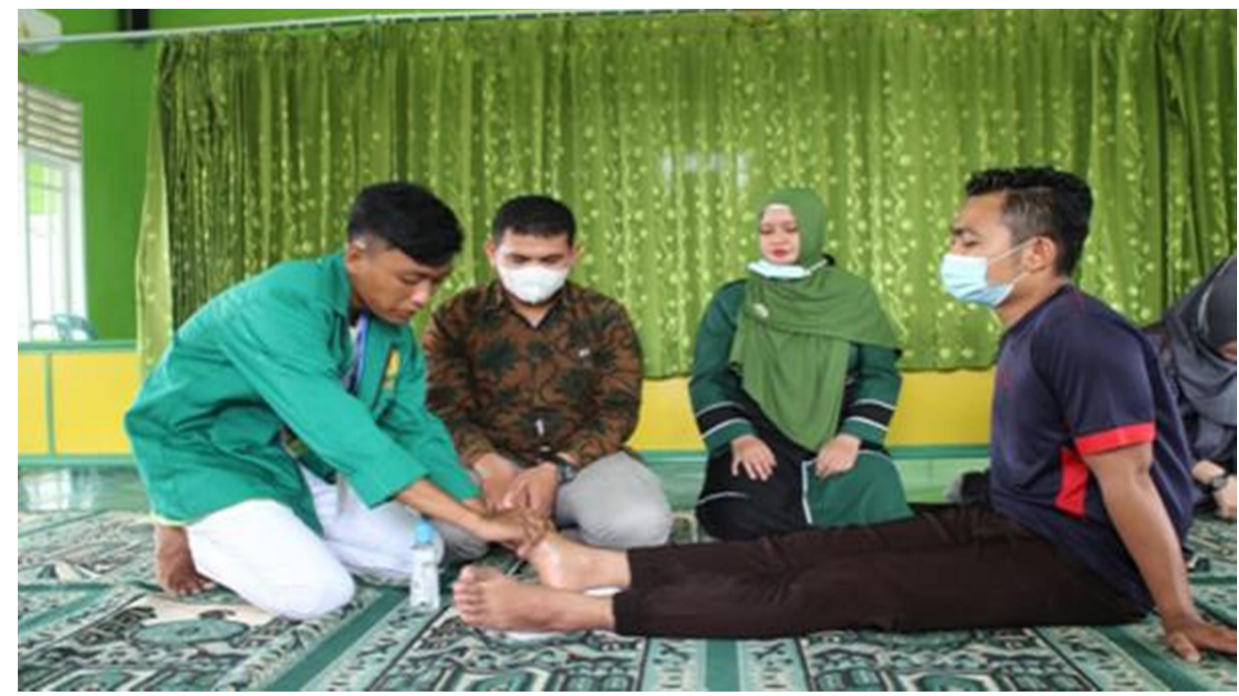

Gambar 3. Para Praktikan Melakukan Terapi Foot Massage di Depan Para Peserta 

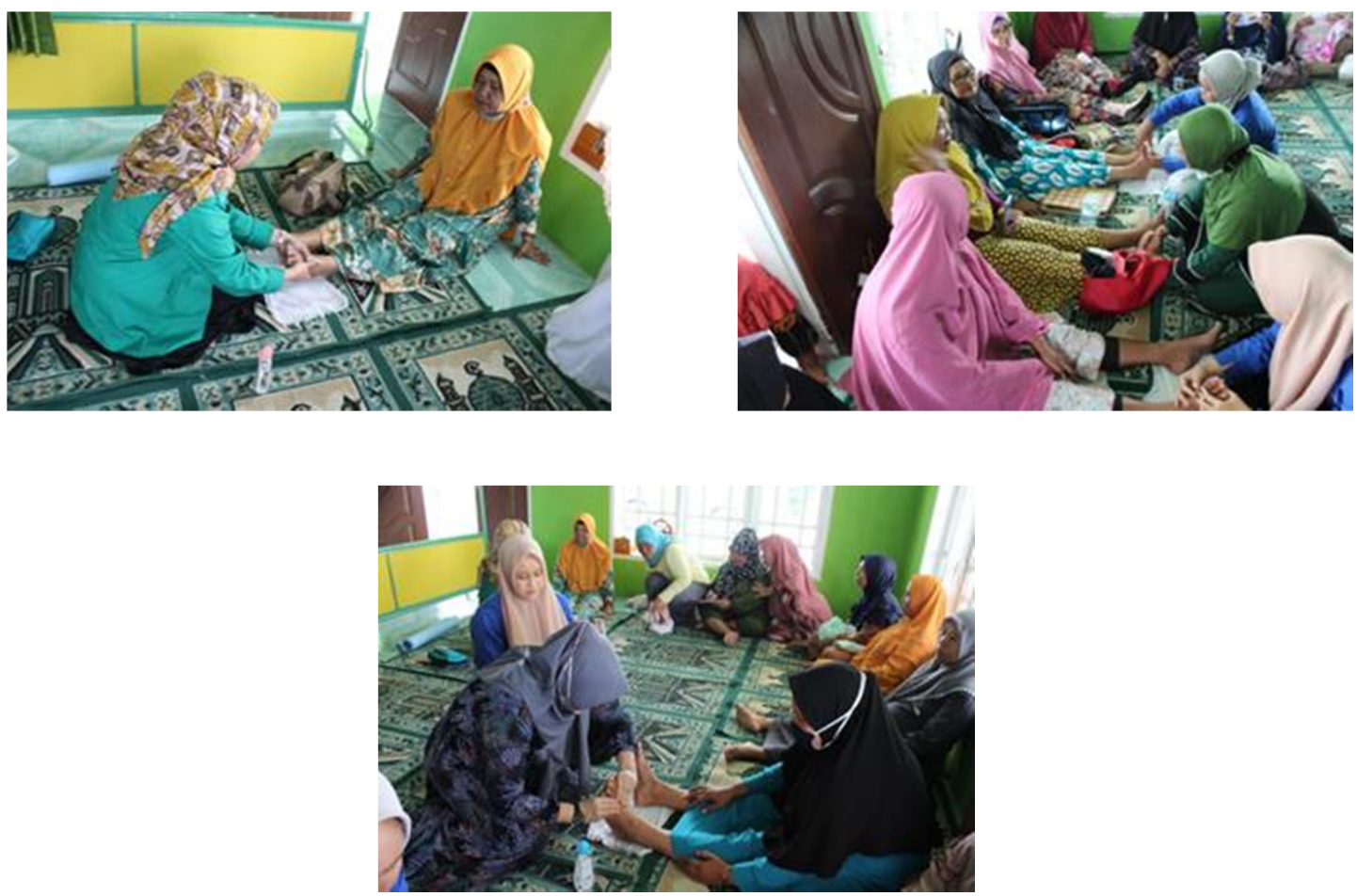

Gambar 4. Pelaksanaan Terapi Foot Massage

Pelaksanaan terapi foot massage berikutnya dilakukan 3 hari berturut turut selama 15 sampai dengan 30 menit. Peserta yang sudah bisa melakukan secara mandiri merasakan kenyamanan dikarenakan otot otot kaki yang terasa kaku menjadi sedikit lentur, ringan saat dibawa berjalan, beberapa peserta menyatakan mampu berjalan di pagi hari untuk berolah raga, nyeri pada kaki sampai dengan anggota badan berkurang, peserta menyatakan lebih rileks, tekanan darah selama terapi terlihat stabil. Perubahan terlihat setelah hari ke 3 pelaksanaan.

Kegiatan ini merupakan kegiatan pengabdian masyarakat yang dilaksanakan oleh staf pengajar Universitas Haji Sumatera Utara yang mengampuh mata kuliah keperawatan medikal bedah dan promosi kesehatan.

Setelah 3 hari pelaksanaan terapi foot message di Tanah Merah Kecamatan Binjai Selatan Kota Binjai, dari hasil wawancara para peserta menyatakan lebih rileks, otot kaki semakin ringan untuk melangkah, efek terapi pijat mengalirkan sirkulasi darah ke persendian, mengalirkan oksigen, mengendurkan ketegangan otot sehingga memperlancar aliran darah kejantung dan menstabilkan tekanan darah (Yanti, 2019).

Tim pengabdian selalu melakukan pemeriksaan tekanan darah sebelum dan sesudah pelaksanaan terapi foot massage serta melakukan wawancara dan mengobservasi keadaan para peserta selama proses terapi dilaksanakan. Hasil pemeriksaan pada peserta yang hipertensi dan rutin melaksanakan terapi tekanan darah mengalami penurunan dan 
Terapi Foot Massage Untuk Menurunkan dan Menstabilkan Tekanan Darah pada Penderita Hipertensi

Kamaliah Ainun, Kristina, Srimis Leini

cenderung stabil. Pijat memberikan relaksasi yang dalam dikarenakan sistem syaraf simpatis yang mengalami penurunan aktivitas dan dapat mengakibatkan penurunan tekanan darah, pijat juga merupakan suatu bentuk latihan pasif yang mampu meningkatkan sirkulasi darah pada tubuh (safitri, 2009).

Terapi foot massage merupakan terapi komplementer yang aman dan mudah untuk dilakukan secara mandiri bermanfaat meningkatkan sirkulasi, mengeluarkan sisa metabolisme, meningkatkan rentang gerak sendi, mengurangi rasa sakit, merelaksasikan otot, dan memberikan rasa nyaman pada pasien (Afianti, 2017).

Hipertensi merupakan penyakit tidak menular yang menjadi masalah serius adalah prevalensinya semakin meningkat di kalangan masyarakat, bahkan tanda dan gejala sering tidak disadari oleh penderita sehingga menjadi pembunuh diam diam (the silent killer of death) menjadi pencetus utama timbulnya penyakit jantung, stroke dan ginjal (Sutanto, 2010). Hipertensi perlu mendapat perhatian dan penanganan khusus baik secara preventif, promotif, kuratif dan rehabilitatif (Arianto, 2018). Penanganan komprehensif bertujuan untuk menurunkan tekanan darah yang dapat dilakukan dengan terapi konvensional maupun terapi non konvensional. Terapi konvensional melalui pemberian obat-obatan anti hipertensi, terapi non konvensioal merupakan terapi komplementer yang dapat dilakukan dengan bekam, akupunktur, tanaman herbal, akupresur dan massage (Ardiyansah, 2019).

Pelaksanaan terapi foot massage yang telah dilakukan dengan rutin sesuai standar operasional prosedur yang sudah diberikan merupakan salah satu cara terbaik untuk menurunkan tekanan darah sistolik dan diastolik, menurunkan kadar hormon stress cortisol, menurunkan sumber depresi dan kecemasan, sehingga tekanan darah akan terus menurun dan fungsi tubuh semakin membaik hal ini sejalan dengan penelitian Zunaidi 2014. Penelitian Nugroho, Asrin, \& Sarwono (2012) juga menunjukkan bahwa foot reflexology lebih efektif menurunkan tekanan darah dibandingkan hipnoterapi.

\section{KESIMPULAN DAN SARAN}

Hipertensi the silent killer of death yang merupakan penyakit serius dapat mengakibatkan kematian yang tiba-tiba tanpa disadari oleh penderita. Prevalensi kasus yang terus meningkat di kalangan masyarakat, khususnya lansia, dan faktor pencetus munculnya penyakit jantung, stroke dan ginjal.

Kegiatan pengabdian masyarakat yang sudah dilaksanakan 3 hari berturut turut selama 10 sampai dengan 15 menit di kelurahan Tanah Merah Kecamatan Binjai Selatan Kota Binjai bahwa kegiatan terapi foot massage memberikan dampak positif peserta 
hipertensi, mengalami rileks, mampu berjalan dengan nyaman tanpa keluhan nyeri, kaku otot berkurang, tekanan darah stabil sistol dan diastol.

Terapi foot massage merupakan terapi komplementer yang aman dan mudah untuk dilaksanakan secara mandiri yang bertujuan memberikan efek relaksasi pada otot-otot yang kaku sehingga terjadi vasodilatasi dan menyebabkan tekanan darah turun secara stabil.

\section{DAFTAR PUSTAKA}

Abduliansyah, M. R. (2018). Analisa Praktik Klinik Keperawatan pada Pasien Hipertensi Primer dengan Intervensi Inovasi Terapi Kombinasi Foot Massage dan Terapi Murrotal Surah Ar-Rahman terhadap Penurunan Tekanan Darah di Ruang Instalasi Gawat Darurat RSUD Abdul Wahab Sjahranie. Karya Ilmiah Akhir. Universitas Muhammadiyah Kalimantan Timur. Diambil dari https://dspace.umkt.ac.id/handle/463.2017/760.

Afianti, N., \& Mardhiyah, A. (2017). Pengaruh Foot Massage terhadap Kualitas Tidur Pasien di Ruang ICU. Jurnal Keperawatan Padjadjaran, 5(1), 86-97. https://doi.org/10.24198/jkp.v5n1.10

Ardiansyah. \& Huriah, T. (2019). Metode Massage Terhadap Tekanan Darah Pada Penderita Hipertensi: a Literatur Review. Jurnal Penelitian Keperawatan, 5(1). https://doi.org/10.32660/jurnal.v5i1.334

Arianto, A., Prastiwi, S., \& Sutriningsih, A. (2018). Pengaruh Terapi Pijat Refleksi Telapak Kaki Terhadap Perubahan Tekanan Darah Pada Penderita Hipertensi. Nursing News, 3(1), 584-594.

Nugroho. I.A., Asrin, \& Sarwono. (2021). Efektifitas Pijat Refleksi Kaki Dan Hipnoterapi Terhadappenurunan Tekanan Darah Pada Pasien Hipertensi. Jurnal Ilmiah Kesehatan Keperawatan, 8(2), 57-63.

Patria, A. (2019). Pengaruh Masase Kaki Terhadap Penurunan Tekanan Darah pada Kelompok Dewasa yang Mengalami Hipertensi. Jurnal Kesehatan Panca Bhakti Lampung, 7(1), 48. https://doi.org/10.47218/jkpbl.v7i1.60

Puthusseril, V. (2006). Special foot massage as a complimentary therapy in palliative care, Indian Journal Palliative Care 12, 71-76.

Putri, S. (2009). Efektivitas Massage Kaki dengan Minyak Essensial Lavender terhadap Penurunan Tekanan Darah. Skripsi. Universitas Sumatera Utara. Diambil dari https://123dok.com/document/download/7q06er3q?page=1.

Sutanto. (2010). Cekal (Cegah dan Tangkal) Penyakit Modern (Hipertensi, Stroke, Jantung, Kolesterol, dan Diabetes). Yogyakarta: Andi.

Yanti, E., Rahayuningrum, D. C., \& Arman, E. (2019). Efektifitas Massase Punggung Dan Kaki Terhadap Tekanan Darah Pada Penderita Hipertensi. Jurnal Kesehatan Medika Saintika, 10(1), 18. https://doi.org/10.30633/jkms.v10i1.305

Zunaidi, A., Nurhayati, S., \& Prihatin, T. W. (2014). Pengaruh Pijat Refleksi Terhadap Tekanan Darah Pada Penderita Hipertensi Di Klinik Sehat Hasta Therapetika Tugurejo Semarang. Prosiding Konferensi Nasional Ii Ppni Jawa Tengah 2014, 5665. 